\title{
Effect of a single-dose of BBV-152 and AZD1222 on Spike antibody titre among healthcare workers previously infected with SARS-CoV-2
}

\section{Debaprasad Parai}

ICMR - Regional Medical Research Centre, Bhubaneswar https://orcid.org/0000-0003-0266-5623 Hari Ram Choudhary

ICMR - Regional Medical Research Centre, Bhubaneswar https://orcid.org/0000-0001-6457-7202

Girish Chandra Dash

ICMR - Regional Medical Research Centre, Bhubaneswar https://orcid.org/0000-0003-2771-5965

\section{Subrat Kumar Sahoo}

ICMR - Regional Medical Research Centre, Bhubaneswar

Matrujyoti Pattnaik

ICMR - Regional Medical Research Centre, Bhubaneswar

Usha Kiran Rout

ICMR - Regional Medical Research Centre, Bhubaneswar

https://orcid.org/0000-0002-2588-3538

Rashmi Ranjan Nanda

ICMR - Regional Medical Research Centre, Bhubaneswar

https://orcid.org/0000-0002-2685-1570

\section{Srikanta Kanungo}

ICMR - Regional Medical Research Centre, Bhubaneswar https://orcid.org/0000-0001-5647-0122 Jaya Singh Kshatri

ICMR - Regional Medical Research Centre, Bhubaneswar https://orcid.org/0000-0003-3616-3402 Sanghamitra Pati ( $\sim$ drsanghamitra12@gmail.com )

ICMR - Regional Medical Research Centre, Bhubaneswar https://orcid.org/0000-0002-7717-5592 Debdutta Bhattacharya ( $\sim$ drdebdutta.bhattacharya@yahoo.co.in )

ICMR - Regional Medical Research Centre, Bhubaneswar https://orcid.org/0000-0001-5199-5288

\section{Short Report}

Keywords: COVID-19, Vaccination, Covaxin, Covishield, Spike IgG antibody

Posted Date: May 21st, 2021

DOI: https://doi.org/10.21203/rs.3.rs-542984/v1 
License: (c) (i) This work is licensed under a Creative Commons Attribution 4.0 International License. Read Full License 


\section{Abstract}

Objective Dissemination of vaccines among the maximum number of recipients is becoming an uphill task in many low and middle-income countries (LMIC). This study was conducted to ease the vaccination load and to reach the highest number of immunities in a population about the neutralizing antibody response.

Methods We followed the vaccination status of 134 healthcare workers (HCWs) among which 59 were previously confirmed SARS-CoV-2 positive by RT-PCR test and 75 naive participants. All of them took two dosages of either BBV-152 or AZD1222 vaccine. Antibodies against SARS-CoV-2 spike and nucleocapsid proteins were measured in two CLIA-based platforms Cobas e411 and ARCHITECT i1000SR.

Results From prior COVID-19 recovered HCWs, 96\% were found to be seropositive and developed a median concentration of $588.0 \mathrm{U} / \mathrm{mL}$ (interquartile range [IQR], 250.0-2500.0 AU/mL) IgG antibody against SARS-CoV-2 S- protein after a single dose of vaccine whereas only $61.3 \%$ of previously noninfected HCWs developed antibody against SARS-CoV-2 S- protein after single dose with a median concentration of $7.27 \mathrm{U} / \mathrm{mL}$ (IQR, 0.4-116.5 AU/mL). A total of $82.7 \% \mathrm{HCWs}$ having no earlier COVID-19 infection history became seropositive after the second dose of vaccine irrespective of gender and age.

Conclusion We found that a single dose of BBV-152 and AZD1222 induced a high concentration of neutralizing IgG antibody in HCWs having a recovery history from COVID-19.

\section{Introduction}

The world is currently facing either the second or third wave of coronavirus disease 2019 (COVID-19) caused by severe acute respiratory syndrome coronavirus 2 (SARS-CoV-2) [1]. Craving for the potential vaccines was started from the beginning of the COVID-19 pandemic and the demand was increased with time as we couldn't find a successful treatment against the virus to date [2]. To keep all the hope alive, the worldwide rollout of vaccines has been started from December 2020 [3]. As much as vaccination coverage with all due speed is the current and most prospective option to tackle the further breakdown of the healthcare systems throughout the countries.

India is currently facing the second wave of the SARS-CoV-2 virus which is more intense, overwhelming and devastating compared to the first one [4]. As of $17^{\text {th }}$ May 2021, India reported 24.96 million confirmed COVID-19 cases with an average weekly spike of 319,497, and a total of 274,390 deaths to date [5]. Two vaccines named BBV-152 (COVAXIN®) and AZD1222 (COVISHIELD ${ }^{\text {TM}}$ ) were initially available in the Indian market after the government approval for emergency use in the country and became part of India's largest vaccination drive started from $16^{\text {th }}$ January 2021. Later, the Gam-COVIDVac (Sputnik V) got the approval and subsequently launched on $14^{\text {th }}$ May 2021 [6]. India has administered 0.184 billion citizens with at least a single dose of either BBV-152 or AZD1222 vaccine and among them, only 0.042 billion people got both the dosages (complete vaccination) as of mid-May [5]. 
Since India is the second most populated country in the world with a population of 1.39 billion, the complete vaccination status is comparatively low $(3.0 \%)$ and the shortage of adequate shots has already started all over the country [4]. The dissemination of vaccines for most of the citizens is among the current ongoing challenges to India and the situation can be bloomed in other LMIC members as well in near future.

In this study, we assessed the spike (S) and nucleocapsid $(\mathrm{N})$ protein IgG titre during baseline and subsequently after each dose of vaccines in $\mathrm{HCWs}$ to understand the requirement of vaccination in the prior COVID-19 infected seropositive HCWs.

\section{Methods}

\section{Study settings}

A total of $134 \mathrm{HCW}$ sere included in this study from January 2021 to April 2021. All of them were fully vaccinated either with BBV-152 or AZD1222 as a part of the first vaccination drive to healthcare and frontline workers, both were approved for emergency use in Odisha, India. Blood samples were collected from all the HCWs before vaccination (Day 0 ) and after 28 days of each dosage of vaccination.

Demographic details such as age, gender, history of COVID-19 infection, the onset of symptoms after vaccination were recorded from time to time. Written informed consent was obtained from each participant and the study was approved by the Institutional Human Ethics Committee of ICMR- Regional Medical Research Centre, Bhubaneswar. No new or reinfection was reported by the cohort participants during the study period.

\section{Detection of IgG antibodies against nucleocapsid protein and spike protein}

IgG antibody against SARS-CoV-2 was measured by two automated chemiluminescence electro assay (CLIA) based platforms, ARCHITECT i1000SR (Abbott Diagnostics, Chicago, USA) and Cobas e411 (Roche Diagnostics $\mathrm{GmbH}$, Mannheim, Germany). IgG antibodies against N-protein were measured by the first platform having $100 \%$ sensitivity ( $95 \%$ confidence of interval [Cl]: $95.89-100 \%$ ) when tested after 14 days post-symptom onset and specificity of $99.63 \%$ (95\% Cl: $99.05-99.90 \%)$ as per the manufacturer provided insert. The cut-off value for this platform was 1.4 index. Roche platform determined the number of antibodies including IgG against the S- protein receptor-binding domain (RBD) which is the primary target of neutralizing antibodies in SARS-CoV-2. The sensitivity of this assay was 98.8 (95\% Cl: 98.10 99.30\%) when samples were collected $\geq 14$ days after RT-PCR positive and the specificity was 99.98 ( $95 \%$ Cl: $99.91-100.00 \%)$. Values $\geq 0.80 \mathrm{U} / \mathrm{mL}$ were considered as positive and $<0.80 \mathrm{U} / \mathrm{mL}$ as negative. The higher detection limit was $2500 \mathrm{U} / \mathrm{mL}$ for 10 -fold diluted samples.

\section{Statistical analysis}

GraphPad Prism 7.00 for Windows (GraphPad Software, La Jolla, California, USA) were used for descriptive statistical analyses. Two-tailed Mann-Whitney test and Wilcoxon matched-pairs signed ranked 
test was performed appropriately depending upon the type of data. The statistical significance threshold was set at $5 \%$.

\section{Results}

Among the $134 \mathrm{HCWs}, 59$ had a previous history of COVID-19 infection confirmed by RT-PCR test and the other $75 \mathrm{HCW}$ s were naive. At baseline in January 2021, total 21 (35.6\%) recovered participants remained IgG positive against $\mathrm{N}$ - protein although 55 (93.2\%) were seropositive against S- protein [Table 1]. We measured the IgG humoral response after 28 days of the first vaccination of all the healthcare workers and found a significant rise in the antibody concentration for those having earlier COVID-19 infection history irrespective of the given vaccine [Figure S1]. For those, the overall median concentration of Sprotein IgG was increased significantly $(p<0.001)$ to $588.0 \mathrm{U} / \mathrm{mL}(\mathrm{IQR}, 250.0-2500.0 \mathrm{AU} / \mathrm{mL})$ from 231.4 $\mathrm{U} / \mathrm{mL}(\mathrm{IQR}, 81.9-359.1 \mathrm{AU} / \mathrm{mL}$ ) observed during baseline [Figure 1]. We also found that a time gap of 180 days from recovery significant amount of humoral response against SARS-CoV-2 persists among the recovered individual [Figure S1]. In case of $75 \mathrm{HCWs}$ with no prior infection history, 46 were found to be seropositive after the first dose and the median concentration was low in comparison with recovered individuals and recorded at 7.27 U/mL (IQR, 0.4-116.5 AU/mL). The mean titre of $\mathrm{N}$ - protein IgG increased to 1.8 index (IQR, 0.66-2.74 index) from 0.98 index (IQR, 0.54-2.0 index) after the first dose of vaccine in HCWs having previous COVID-19 history although the change was statistically non-significant $(p=0.06)$. The antibody magnitude was further changed after the second dose of the vaccine in both the HCWs categories of prior COVID-19 infection and non-exposed. Median S- protein IgG was measured as 1674.0 $\mathrm{U} / \mathrm{mL}(\mathrm{IQR}, 610.3-2500.0 \mathrm{AU} / \mathrm{mL})$ and $46.5 \mathrm{U} / \mathrm{mL}(\mathrm{IQR}, 5.84-839.9 \mathrm{AU} / \mathrm{mL})$ for those categories, respectively [Figure 1].

\section{Discussion}

In this study, we aimed to investigate the humoral responses against two currently available vaccines BBV-152 and AZD1222 in India. Being the second-largest demography in the world, it is nevertheless challenging to vaccinate a sizeable population to acquire herd immunity. The second wave of the COVID19 with high morbidity reemphasized the need for vaccination to curtail the mortality and severity of the disease. The study findings even limited in a small cohort suggest a single dose of either of the vaccine can develop a higher level of neutralizing immune response in HCWs with prior COVID-19 infection history compare to non-infected individual.

We did not find any significant difference in antibody development across gender $(p=0.350)$ and age groups $(p=0.556)$, thus indicating the universality of both the vaccines. Although there are few reports about the severe adverse effects of vaccines around the world [7, 8], we did not record such severe postvaccination complications among our participants during periodic follow-up. 27 prior COVID-19 positive HCWs $(45.7 \%)$ reported to face mild symptoms (average score $=1.44)$ compared to $32.0 \%(n=24)$ in noninfected HCWs (average score= 1.33). Most commonly observed symptoms like fever, myalgia, headache and body ache were observed which might be due to normal immunological response. Although a 
handful of works have been published with other vaccines in other countries, the data presented here is the first such report with BBV-152 and AZD1222 in this region $[9,10]$. It may be noted that our study was confined to HCWs and may not be extrapolated to the general population.

Our study findings generated preliminary evidence to consider previous infection status before vaccination for optimization of vaccine policy in view of the current situation in India and a possible future scenario in any country categorised as LMIC. However, follow up with a larger cohort at periodic interval can help us in understanding the protective effect of antibody after $1^{\text {st }}$ dose of vaccine in Covid19 recovered individual.

\section{Declarations}

\section{Ethics Approval}

The study was ethically approved by the institutional human ethical committee of ICMR - Regional Medical Research Centre, Bhubaneswar.

\section{Declaration of Competing Interest}

The authors have no competing interests in any form.

\section{Acknowledgement}

The authors gratefully acknowledge all the healthcare workers for their tireless dedication at each level to fight COVID-19 and for voluntarily participating in this cohort study. The authors are thankful to the Indian Council of Medical Research, New Delhi for providing funding support in this study.

\section{References}

1. Taboada M, González M, Alvarez A, Eiras M, Costa J, Álvarez J, et al. First, second and third wave of COVID-19. What have we changed in the ICU management of these patients? J Infect 2021; 82:e14e15.

2. Brüssow H. Efforts towards a COVID-19 vaccine. Environ Microbiol 2020; 22:4071-4084.

3. Mathieu E, Ritchie H, Ortiz-Ospina E, Roser M, Hasell J, Appel C, et al. A global database of COVID-19 vaccinations. Nat Hum Behav. 2021. https://doi.org/10.1038/s41562-021-01122-8

4. India's COVID-19 emergency. Lancet. 2021. 357: P1683. https://doi.org/10.1016/S01406736(21)01052-7

5. COVID-19 Dashboard. MoHFW, Government of India. 2021. https://www.mohfw.gov.in/ [Accessed on 18th May 2021]

6. Kumar VM, Pandi-Perumal SR, Trakht I, Thyagarajan SP. Strategy for COVID-19 vaccination in India: the country with the second highest population and number of cases. NPJ Vaccines 2021; 6:60. 
7. Kaur RJ, Dutta S, Bhardwaj P, Charan J, Dhingra S, Mitra P, et al. Adverse events reported from COVID19 vaccine trials: a systematic review. Indian J Clin Biochem 2021; 1-13.

8. Menni C, Klaser K, May A, Polidori L, Capdevila J, Louca P, et al. Vaccine side-effects and SARS-CoV-2 infection after vaccination in users of the COVID Symptom Study app in the UK: a prospective observational study. Lancet Infect Dis 2021; S1473-3099(21)00224-3.

9. Reynolds CJ, Pade C, Gibbons JM, Butler DK, Otter AD, Menacho K, et al. Prior SARS-CoV-2 infection rescues $B$ and T cell responses to variants after first vaccine dose. Science 2021; eabh1282.

10. Saadat S, Rikhtegaran Tehrani Z, Logue J, Newman M, Frieman MB, Harris AD, et al. Binding and neutralization antibody titers after a single vaccine dose in health care workers previously infected with SARS-CoV-2. JAMA 2021; 325:1467-1469.

\section{Tables}

Table 1. Demographic characteristics of 134 healthcare workers and their humoral immune response.

\begin{tabular}{|c|c|c|c|c|}
\hline \multirow{2}{*}{\multicolumn{2}{|c|}{ Variables }} & \multicolumn{2}{|c|}{ Previous infection of COVID-19 } & \multirow[t]{2}{*}{ P-Value } \\
\hline & & Yes (59) & No (75) & \\
\hline \multicolumn{2}{|c|}{ Median Age in years (IQR) } & $32.0(26-43)$ & $33.0(26-45)$ & 0.556 \\
\hline \multicolumn{5}{|l|}{ Sex } \\
\hline \multicolumn{2}{|l|}{ Male } & $49(65.3 \%)$ & $43(72.9 \%)$ & \multirow[t]{2}{*}{0.350} \\
\hline \multicolumn{2}{|l|}{ Female } & $26(34.7 \%)$ & $16(27.1 \%)$ & \\
\hline \multicolumn{2}{|c|}{ Median of months from COVID-19 recovery (IQR) } & $4.0(4.0-5.0)$ & - & - \\
\hline \multicolumn{5}{|c|}{ SARS-CoV-2 IgG } \\
\hline N protein & O Day & $21(35.6 \%)$ & $0(0.0 \%)$ & $0.000^{*}$ \\
\hline \multirow{2}{*}{$\begin{array}{l}\text { Positive } \\
\text { ( } \geq 1.4 \text { index) }\end{array}$} & 28 Days & $34(57.6 \%)$ & $3(4.0 \%)$ & $0.000^{*}$ \\
\hline & 56 Days & $35(59.3 \%)$ & $9(12.0 \%)$ & $0.000^{*}$ \\
\hline \multirow{3}{*}{$\begin{array}{l}\text { S protein } \\
\text { Positive } \\
(\geq 0.8 \mathrm{U} / \mathrm{ml})\end{array}$} & 0 Day & $55(93.2 \%)$ & $0(0.0 \%)$ & $0.000^{*}$ \\
\hline & 28 Days & $57(96.0 \%)$ & $46(61.3 \%)$ & $0.000^{*}$ \\
\hline & 56 Days & 59 (100.0\%) & $62(82.7 \%)$ & $0.001^{\star}$ \\
\hline
\end{tabular}

${ }^{*}$ p-value significant at $<0.05$

\section{Figures}


A.
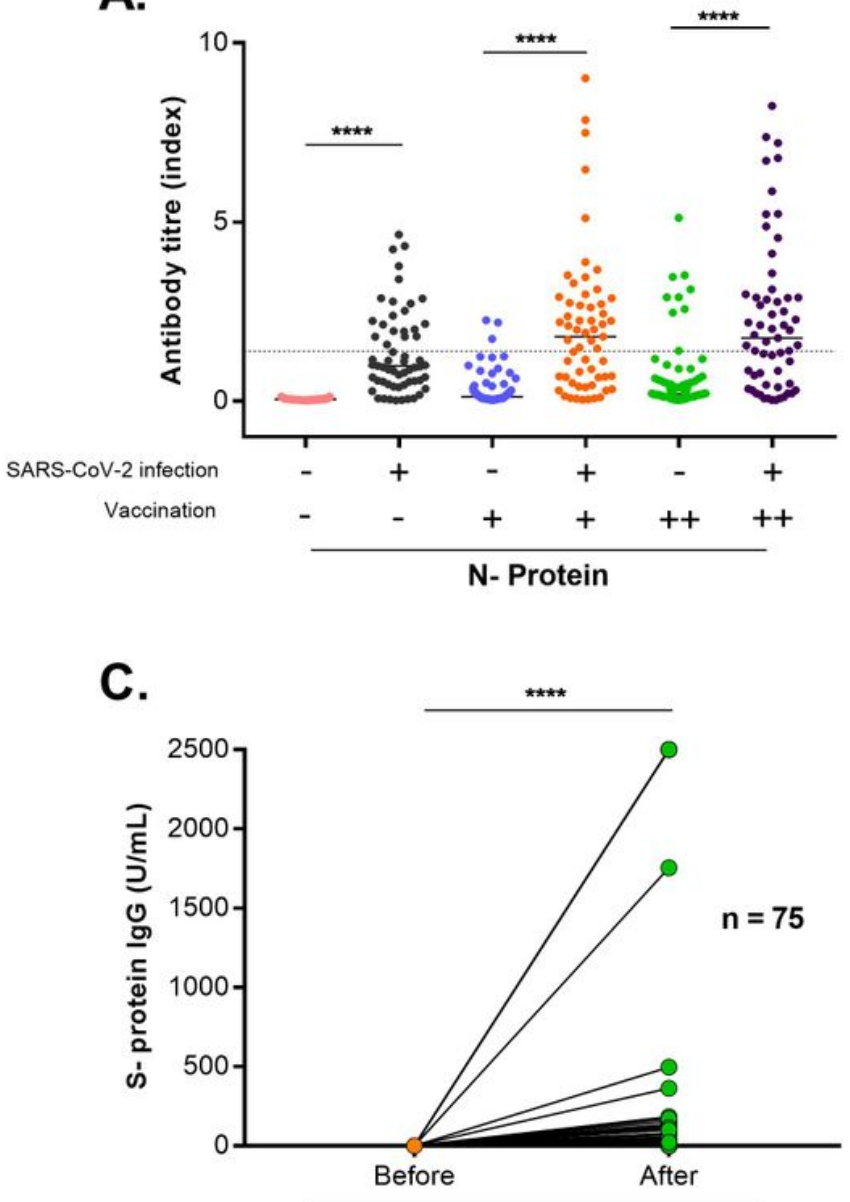

Vaccination status (non-infected)
B.

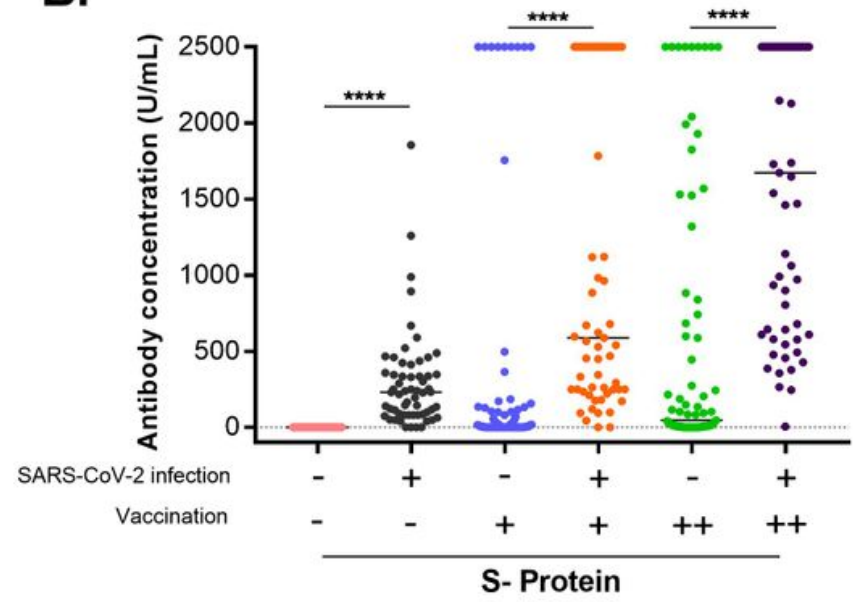

D.

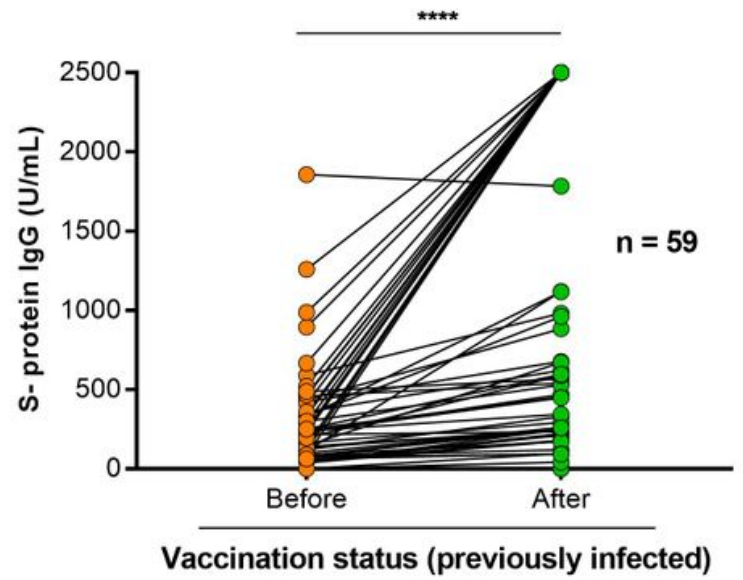

\section{Figure 1}

Antibody responses against SARS-CoV-2 N-protein and S- protein at baseline and after vaccination in previously COVID-19 infected and non-infected HCWs (A \& B). Pair-wise comparison of S- protein IgG response after a single dose of vaccine in prior COVID-19 infected and non-infected HCWs (C \& D). $p<0.05$ was considered as significant.

\section{Supplementary Files}

This is a list of supplementary files associated with this preprint. Click to download.

- SupplementaryFile.docx 